\title{
Solubilization of ibuprofen for freeze dried parenteral dosage forms
}

\author{
MAJA PRESKAR ${ }^{1}$ \\ TOMISLAV VRBANEC ${ }^{1}$ \\ FRANC VREČER ${ }^{1,2}$ \\ PRIMOŽ ŠKET ${ }^{3}$ \\ JANEZ PLAVEC ${ }^{3}$ \\ MIRJANA GAŠPERLIN ${ }^{2}$ \\ ${ }^{1}$ Krka d.d. Novo mesto, SI- 8000 Novo \\ mesto, Slovenia \\ ${ }^{2}$ University of Ljubljana, Faculty of \\ Pharmacy, SI- 1000, Ljubljana \\ Slovenia \\ ${ }^{3}$ Slovenian NMR Center, National \\ Institute of Chemistry, SI-1000 \\ Ljubljana, Slovenia
}

Accepted September 9, 2018

Published online October 29, 2018

\begin{abstract}
Ibuprofen, a weakly acidic non-steroidal anti-inflammatory drug having poor aqueous solubility, is a challenging drug for the development of pharmaceutical formulations, resulting in numerous research attempts focusing on improvement of its solubility and consequently bioavailability. Most studies have been done for solid dosage forms, with very little attention paid to parenterals. Hence, the main purpose of the present study was to enhance ibuprofen solubility as a result of formulation composition and the freeze drying process. Moreover, the purpose was to prepare a freeze dried dosage form with improved ibuprofen solubility that could, after simple reconstitution with water for injection, result in an isotonic parenteral solution. Solubility of ibuprofen was modified by various excipients suitable for parenteral application. Drug interactions with selected excipients in the final product/lyophilisate were studied by a combined use of XRPD, DSC, Raman and ssNMR. Analyses of lyophilized samples showed solubility enhancement of ibuprofen and in situ formation of an ibuprofen salt with the alkaline excipients used.
\end{abstract}

Keywords: ibuprofen, solubility enhancement, freeze drying, physicochemical characterization

One of the most important aspects of formulation development in the pharmaceutical industry is to achieve adequate bioavailability in order to provide sufficient dosing of the drug. It mostly depends on aqueous solubility of the drug and, in case of oral dosage forms, on its intestinal permeability characteristics, as specified by the biopharmaceutical classification system (BCS) $(1,2)$. Considering the fact that solid pharmaceutical products represent almost $90 \%$ of all pharmaceutical market, that $40 \%$ of well-known drugs and $70 \%$ of new drug candidates are poorly aqueous soluble, prediction of bioavailability and improvement of solubility is of crucial importance (1-3). Therefore, assurance of appropriate drug solubility is important and is a great challenge to scientists in formulating solid and liquid dosage forms to achieve sufficient solubility and physicochemical stability of poorly aqueous soluble drugs $(4,5)$.

\footnotetext{
*Correspondence; e-mail: maja.preskar@krka.biz
} 
Ibuprofen (IBP) is a weak acid, classified as BCS Class II (6) drug. It is a member of the well-established nonsteroidal anti-inflammatory drugs (NSAIDs) and is widely used for acute or chronic pain relief. Due to its poor aqueous solubility $\left(0.12 \mathrm{mg} \mathrm{mL}^{-1}\right.$ at $\left.25^{\circ} \mathrm{C}\right)(5)$ and high dosing (maximum single dose is $800 \mathrm{mg}$ ) (7), it presents a great challenge to formulating both solid and liquid dosage forms, and thus also parenteral ones.

Various techniques for IBP solubilization in solid oral formulations have been described in the literature: lipid based drug delivery system (8), solid lipid nanoparticles or spray drying of amorphous IBP nanoparticles for the production of granules with enhanced drug release $(9,10)$, solubilization by surfactants $(7,11)$, solid dispersion techniques $(12,13)$, fusion method with Poloxamer 407 (14) and also freeze drying to form IBP crystals (15) or for orodispersible tablet (ODT) formulation (16). The approaches described for liquid formulations are mainly focused on solubility enhancement by cyclodextrin complexation $(17,18)$, addition of hydrotropic agents (19), $\mathrm{pH}$ modification (7), surfactant and cosolvent addition (20-22) and salt formation $(23,24)$. Use of co-solvents is by far the most common and effective method, although recently the use of complexing agents such as cyclodextrins has greatly increased owing to their positive effect on drug stability and bioavailability (5).

Each technique exhibits advantages and disadvantages and the choice depends on drug characteristics, pharmaceutical dosage form and route of application (2). Market research shows that despite the fact that intravenous (i.v.) application has a rapid onset of action and diminished gastric irritations (6), only three products have been approved for parenteral administration by the Food and Drug Administration (FDA), in comparison with 146 oral IBP formulations (25). According to the European largest market, Germany, only one parenteral dosage form with IBP is present, registered as Pedea ILO $5 \mathrm{mg} \mathrm{mL}^{-1}$ solution for injection, while, on the other hand, 232 products are reported for oral application (26). Moreover, the currently available i.v. solution for injections with IBP in higher concentration (> $10 \mathrm{mg} \mathrm{mL}^{-1}$ ), should be reconstituted with $0.9 \% \mathrm{NaCl}$, Glucose or Ringer solution before use (27), which consequently means that osmolality of the final product depends on the osmolality of the solution used for reconstitution.

The IBP molecule (Fig. 1) is characterized by a bulky aromatic ring with a methylpropyl side chain and an ionizable functional carboxyl group $(\mathrm{COOH})$, making it nonpolar in nature and thus poor water soluble, especially below its $\mathrm{p} K_{\mathrm{a}}\left(\mathrm{p} K_{\mathrm{a}}\right.$ is 4.41) (5). As mentioned above, increase in IBP solubility can occur from a variety of solute-solute, solute-solvent or solvent-solvent interactions (22). In solute-solvent interactions, IBP can act as a Lewis acid (proton donor) and establish hydrogen bonds with the proton acceptor group in the solvent but, on the other hand, can also act as a proton acceptor compound by means of its carbonyl and hydroxyl group (28).

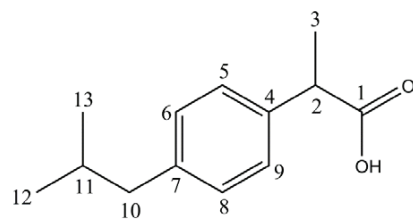

Fig. 1. Chemical structure of ibuprofen. Atom numbering used in the current study is indicated. 
However, solute-solvent interaction with alkaline excipients, present in the preparation process of freeze dried formulations, raises the question whether salt or co-crystals can be formed. Salts and co-crystals are multicomponent solids that differ in molecular components. Salts contain cations and anions, while co-crystals with no proton transfer (29) comprise neutral molecules bonded together by weak bonds such as H-bonds and/or van der Walls interactions, where at least one of the components belongs to an active pharmaceutical ingredient (30).

Nevertheless, the aim of our study was to develop and study a freeze dried product capable of i.v. application by simple reconstitution with a predetermined quantity of water for injection (WFI), with no need for additional isotonization. In addition, the mechanism of IBP solubilisation was studied.

Thus far, a freeze dried product with IBP was only published in research papers as the IBP-cyclodextrin complex (18) and IBP lysinate (23), which provided limited data on isotonicity, which is one of the most important parameters for parenteral application. Thus, we strongly believe that achieving enhanced drug solubility and isotonicity by composition formula with freeze drying and reconstituting of a parenteral IBP product with WFI only, could open new possibilities in pharmaceutical technology and medical treatments.

\section{EXPERIMENTAL}

\section{Materials}

Crystalline ibuprofen was provided by Krka d.d., Slovenia. To prepare the lyophilized product, we used ingredients for $\mathrm{pH}$ adjustment (1 M sodium hydroxide $(\mathrm{NaOH})$, provided by Merck KGAA and L-arginine, provided by Ajinomoto Omnichen n.v.), isotonic agents (mannitol, provided by Roquette Italy s.p.a., sodium chloride $(\mathrm{NaCl})$, provided by Salinen Austria AG, sucrose, provided by Tereos France and glucose, provided by Tereos Syral s.a.s.) and co-solvent (tertiary butyl alcohol, provided by Sigma Aldrich, USA). Sodium salt of ibuprofen was made in Krka's laboratory (31).

\section{Preparation of freeze dried powders}

Solutions for freeze drying were prepared according to parenteral requirements with regard to tonicity and $\mathrm{pH}$. Quantity of mannitol, glucose, sucrose or sodium chloride was defined by osmolality criteria in a range of $280-320$ mosmol kg-1 of reconstituted powder, while the quantity of L-arginine or sodium hydroxide according to $\mathrm{pH}$ criteria (following optimal physiological $\mathrm{pH}$ of 7.4), which is also in favor of better IBP solubility at $\mathrm{pH}>4.5$ (8). IBP was dissolved in tertiary butyl alcohol and further mixed with an aqueous solution of $\mathrm{NaOH}$ or L-arginine and mannitol, $\mathrm{NaCl}$, sucrose or glucose, followed by filtration through $0.22 \mu \mathrm{m}$ filters. IBP concentration was $12 \mathrm{mg} \mathrm{mL}^{-1}$. Table I gives an overview of the developed formulations.

$2 \mathrm{~mL}$ of prepared solution was filled in $10 \mathrm{~mL}$ vials and lyophilized. Minifast 10 was used to freeze dry the samples at $-45^{\circ} \mathrm{C}$ for $3 \mathrm{~h},-30^{\circ} \mathrm{C}$ and pressure of $177 \mu \mathrm{bar}$ for $12 \mathrm{~h}$, followed by $5 \mathrm{~h}$ at $-10{ }^{\circ} \mathrm{C}$ and $4 \mathrm{~h}$ at $5^{\circ} \mathrm{C}$. Secondary drying was performed at $30^{\circ} \mathrm{C}$ for $6 \mathrm{~h}$ at $177 \mu$ bar.

Freshly prepared lyophilized powders were subjected to further characterization. 
Table I. Composition formula for F1-F6 samples (in $m g L^{-1}$ before lyophilization)

\begin{tabular}{|c|c|c|c|c|c|c|}
\hline & $\mathrm{F} 1$ & F2 & F3 & F4 & F5 & F6 \\
\hline Ibuprofen & $12 \mathrm{mg}$ & $12 \mathrm{mg}$ & $12 \mathrm{mg}$ & $12 \mathrm{mg}$ & $12 \mathrm{mg}$ & $12 \mathrm{mg}$ \\
\hline Mannitol & & $150 \mathrm{mg}$ & & $148 \mathrm{mg}$ & & \\
\hline Sodium chloride & $27 \mathrm{mg}$ & & $24 \mathrm{mg}$ & & & \\
\hline Sucrose & & & & & $148 \mathrm{mg}$ & \\
\hline Glucose & & & & & & $202.4 \mathrm{mg}$ \\
\hline Tertiary butyl alcohol & $156 \mathrm{mg}$ & $156 \mathrm{mg}$ & $156 \mathrm{mg}$ & $156 \mathrm{mg}$ & $156 \mathrm{mg}$ & 156 mg \\
\hline L-arginine & $10.4 \mathrm{mg}$ & $10 \mathrm{mg}$ & & & & \\
\hline $1 \mathrm{~mol} \mathrm{~L}^{-1} \mathrm{NaOH}$ & & & $59.9 \mathrm{mg}$ & $57.8 \mathrm{mg}$ & $54 \mathrm{mg}$ & $50.6 \mathrm{mg}$ \\
\hline WFI & up to $1 \mathrm{~mL}$ & up to $1 \mathrm{~mL}$ & up to $1 \mathrm{~mL}$ & up to $1 \mathrm{~mL}$ & up to $1 \mathrm{~mL}$ & up to $1 \mathrm{~mL}$ \\
\hline
\end{tabular}

\section{Measurement of reconstitution time}

Each vial with lyophilized powder contained $24 \mathrm{mg}$ of IBP. In order to prepare the targeted IBP concentration for parenteral preparation, $4 \mathrm{mg} \mathrm{mL}^{-1}, 6 \mathrm{~mL}$ of WFI was added to the vial with the finished product (4). Afterwards, the vials were manually shaken and the time was measured until a clear solution, as determined by the naked eye, was obtained.

\section{Solubility determination}

IBP solubility was determined by the following procedure: samples of lyophilized powder and pure drug were weighted in vials, where $1 \mathrm{~mL}$ of ultrapure water was added to the final IBP concentration of $40 \mathrm{mg} \mathrm{mL}^{-1}$. Experiments were performed at ambient temperature. Vials were shaken at $300 \mathrm{rpm}$ and after one hour were transferred to a $1.5 \mathrm{~mL}$ Eppendorf tube and centrifuged at $10000 \mathrm{~g}$ for two minutes. Supernatants were then diluted with water and analyzed in duplicates by HPLC (HPLC Agilent 1260 Series) with column X-Bridge C18 $75 \times 4.6 \mathrm{~mm} 2.5 \mu \mathrm{m}$ particles. Mobile phase: gradient elution; mobile phase A $0.1 \%$ concentrated phosphoric acid; mobile phase B acetonitrile as 55:45 (V/V) mixture. Flow was $1.25 \mathrm{~mL} \mathrm{~min}^{-1}$, column temperature: $60^{\circ} \mathrm{C}$, injection volume: $10 \mu \mathrm{L}$ and detection wavelength: $220 \mathrm{~nm}$.

\section{Osmolality test}

An automatic freezing point osmometer (Knauer) was employed to measure freezing point depression. A dilution was made with milli-Q water to the final volume of $6 \mathrm{~mL}$. Sample volume of $6.0 \mathrm{~mL}$ was measured and the vials were shaken until lyophilized powder was completely dissolved. The measurement run was fully automated after the sample was injected. Osmolality was then calculated, taking into account the dilution factor of the sample solution.

\section{Ibuprofen and related substance content determination}

Determination of the IBP and related substances in lyophilized powder was performed by dissolving lyophilized samples in a suitable quantity of acetonitrile/water 50:50 
$(V / V)$ mixture. Analytical method was developed according to the analytical method for IBP, which is described in the European Pharmacopoeia.

Sample preparation for content determination: the content of the vial was quantitatively transferred into a $50 \mathrm{~mL}$ volumetric flask, rinsed and diluted with solvent to the final volume. $4.0 \mathrm{~mL}$ of sample solution was transferred with a pipette into a $10 \mathrm{~mL}$ volumetric flask and diluted with solvent to the final volume. Quantification of samples was done using a UV-spectrophotometer (Waters Acquity Arc) at a wavelength of $221 \mathrm{~nm}$. Chromatographic conditions for the content were: column: Xbridge shield, $50 \mathrm{~mm} \times 4.6 \mathrm{~mm}$ i.d., $5 \mu \mathrm{m}$ particles. Mobile phase: isocratic elution; $0.1 \%$ phosphoric acid/acetonitrile 55:45 (V/V); flow was approximately $1.2 \mathrm{~mL} \mathrm{~min}^{-1}$; injection $10 \mu \mathrm{L}$; column $t=40^{\circ} \mathrm{C}$, sample $t=25^{\circ} \mathrm{C}$.

Sample preparation for determination of related substances: the content of the vial was quantitatively transferred into a $25 \mathrm{~mL}$ volumetric flask, rinsed and diluted with solvent to the final volume. Chromatographic conditions for related substances were: column: Ascentis Express C18, $150 \mathrm{~mm} \times 4.6 \mathrm{~mm}$ i.d., $2.7 \mu \mathrm{m}$ particles. Mobile phase: gradient elution; mobile phase A $0.1 \%$ phosphoric acid/acetonitrile $(V / V)$; mobile phase B $0.1 \%$ phosphoric acid/acetonitrile $(V / V)$ as mixtures $A: B=65: 35, A: B=53: 47$ and $A: B=10: 90$. Flow was approximately $1.2 \mathrm{~mL} \mathrm{~min}^{-1}$; injection $5 \mu \mathrm{L}$; column temperature $t=45^{\circ} \mathrm{C}$, sample temperature $t=25^{\circ} \mathrm{C}$. All analyses were performed in duplicate.

\section{Differential scanning calorimetry (DSC)}

A Mettler Toledo DSC1 was used to study the thermal behavior of IBP and its changes in F1-F4 samples. Approximately $3 \mathrm{mg}$ samples were weighted in standard aluminum pans and sealed with perforated lids. An empty pan was used as a reference. Samples were heated from 0 to $220^{\circ} \mathrm{C}$ at a heating rate of $10{ }^{\circ} \mathrm{C} \mathrm{min}^{-1}$ in a nitrogen atmosphere with $40 \mathrm{~mL} \mathrm{~min}^{-1}$ flow.

\section{Raman mapping}

Raman technique was used to evaluate drug interactions and changes in the formulations. For each given sample, $2 \mathrm{~cm} \times 2 \mathrm{~cm}$ area of lyophilized powder was transferred onto microscopic glass and then pressed by hand to get a flat surface of the material. Powder chemical analysis was done by Raman point-by-point mapping experiments using a Senterra dispersive Raman microscope (Bruker Optics, Germany) equipped with a $785 \mathrm{~nm}$ laser using maximum laser power $(100 \mathrm{~mW})$. Integration time was set to $10 \mathrm{~s}$ per spectrum with 2 co-additions. Mapping spectra were extracted directly from the experiment as the average of 2 spectra of each point. The objective used was a 20× confocal objective (Olympus Microscope, Japan) with a $50 \mu \mathrm{m}$ pinhole. The analyzed surface was $800 \mu \mathrm{m} \times 1050 \mu \mathrm{m}$ with step size in $x$-axis $20 \mu \mathrm{m}$ and in $y$-axis $21 \mu \mathrm{m}$, which gave a total of 2091 points (spectra). The most representative spectra were chosen and acquired in an area from 1800 to $450 \mathrm{~cm}^{-1}$. All the data were acquired and manipulated by Bruker Optics software OPUS version 7.5.

\section{X-ray powder diffractometry studies (XRPD)}

X-ray diffractograms were obtained using a PANalytical X'PertPro (The Netherlands) with $\mathrm{Cu} \mathrm{K} \alpha$ radiation $\left(1.5418 \times 10^{-10} \mathrm{~m}\right)$ at $45 \mathrm{kV}$ and $40 \mathrm{~mA}$. Samples were prepared in 
holders with a $16 \mathrm{~mm}$ diameter and $2 \mathrm{~mm}$ depth using the backfilling method. The scanning angle ranged from $3.0-32.5^{\circ}$ of $2 \Theta$; the steps were $0.0334^{\circ}$ of $2 \Theta$, and the counting time was 250 s per step.

\section{Solid state nuclear magnetic resonance (ssNMR)}

All solid-state NMR experiments were performed on an Agilent Technologies NMR System $600 \mathrm{MHz}$ NMR spectrometer equipped with a $3.2 \mathrm{~mm}$ NB Double Resonance HX MAS Solids Probe. Larmor frequencies of carbon and proton nuclei were $150.76 \mathrm{MHz}$ and $599.48 \mathrm{MHz}$. Samples were in the form of lyophilized powders. Cross polarization (CP) and magic-angle spinning (MAS) solid-state NMR were used in ${ }^{13} \mathrm{C}$ experiments with highpower proton decoupling during acquisition. Acquisition time for ${ }^{13} \mathrm{C}$ experiments was $0.02 \mathrm{~s}$ and repetition delays were 5 or $600 \mathrm{~s}$ depending on the sample. The number of scans was between 10 and 11220 . All spectra were recorded at a spinning rate of $16 \mathrm{kHz} .{ }^{13} \mathrm{C}$ chemical shifts were externally referenced to the adamantine peak ( $\delta 38.3$ ppm relative to tetramethylsilane). The one-pulse sequence and magic-angle spinning (MAS) were used in ${ }^{1} \mathrm{H}$ experiments. Acquisition time for ${ }^{1} \mathrm{H}$ experiments was $0.1 \mathrm{~s}$. Repetition delay of $5 \mathrm{~s}$ was applied in all experiments. The number of scans was 16 . All spectra were recorded at a spinning rate of $16 \mathrm{kHz} .{ }^{1} \mathrm{H}$ chemical shifts were externally referenced to the adamantine peak ( $\delta 1.85$ ppm relative to tetramethylsilane).

\section{RESULTS AND DISCUSSION}

Six lyophilized samples of IBP were prepared and subjected to further characterization to study the solubility enhancement of IBP, its mechanism and osmolality of dissolved powder.

\section{Reconstitution time and osmolality}

Reconstitution time was a key criterion for further evaluation of the prepared IBP samples. Final products were in the form of lyophilisates, which generally implies a solid and highly porous structure with enlarged total surface area and high dissolution rate characteristics (32). Therefore, fast reconstitution of powder upon addition of water was expected. Freeze dried IBP products were developed according to compositions presented in Table I, with special advantages of being reconstituted into an isotonic product with only WFI.

Results for reconstitution time, given in Table II, generally show that dissolution of samples F3 and F1 containing $\mathrm{NaCl}$ was faster than that of F2 and F4 with mannitol, but still the difference between F1 (52 s) and F2 (53 s) is not drastic. On the other hand, there is a clear difference in reconstitution time between $\mathrm{F} 3$ and $\mathrm{F} 4$, both of which contain $\mathrm{NaOH}$, but differ in the isotonic agent present ( $\mathrm{NaCl}$ in $\mathrm{F} 3$ and mannitol in $\mathrm{F} 4)$. The variation can be attributed to different solubility of mannitol $\left(182 \mathrm{mg} \mathrm{mL}^{-1}\right)$ and $\mathrm{NaCl}\left(357 \mathrm{mg} \mathrm{mL}^{-1}\right)$ (33), in favour of the latter. Samples F5 and F6, despite high solubility (33) of sucrose (2000 mg $\left.\mathrm{mL}^{-1}\right)$ and glucose $\left(1000 \mathrm{mg} \mathrm{mL}^{-1}\right)$, still did not dissolve upon reconstitution, which could be a consequence of the composition formula and/or non-optimal technological process; therefore formulations F5 and F6 were excluded from further analyses. 
Table II. Results of the reconstitution time and osmolality of samples F1-F6

\begin{tabular}{lcccccc}
\hline & F1 & F2 & F3 & F4 & F5 & F6 \\
\hline Reconstitution time (s) & 52 & 53 & 30 & 60 & $\begin{array}{c}\text { did not } \\
\text { dissolve }\end{array}$ & $\begin{array}{c}\text { did not } \\
\text { dissolve }\end{array}$ \\
Osmolality (mosmol kg m $\left.^{-1}\right)$ & 320 & 313 & 291 & 315 & - & - \\
\hline
\end{tabular}

Osmolality study, presented in Table II, was performed only on samples that, after reconstitution with $6 \mathrm{~mL}$ of WFI, resulted in a clear solution. Obtained results strongly confirm the isotonicity of reconstituted formulations F1 to F4 and indicate that a physiologically acceptable product can be produced, which was also one of the challenging goals of the present study. However, an additional research aim was solubility enhancement, which mechanism will be investigated further by other methods and discussed accordingly.
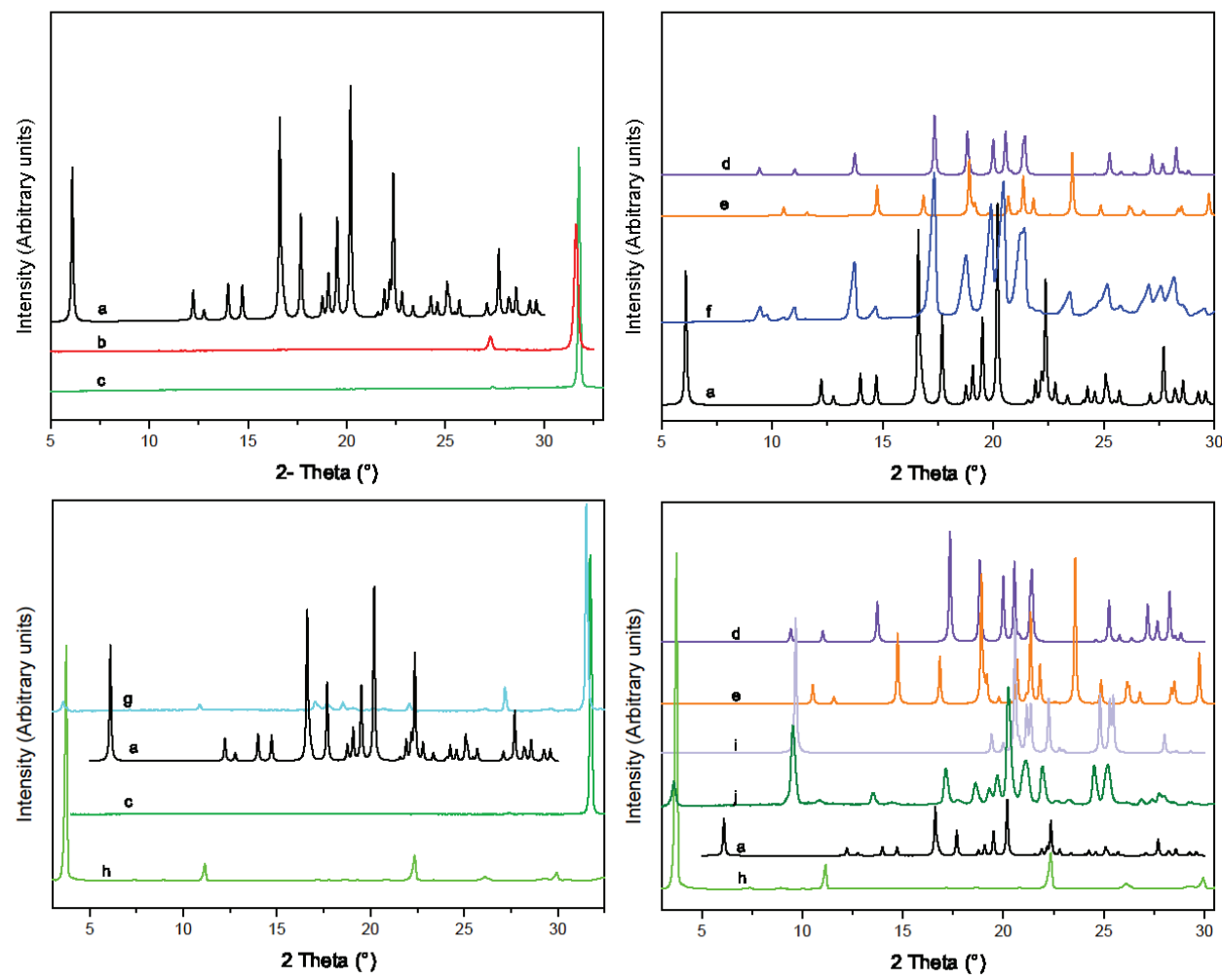

Fig. 2. X-ray diffractograms of: a) crystalline IBP, b) sample F1 (diffractogram a), c) NaCl, d) mannitol $\alpha$, e) mannitol $\beta, \mathrm{f}$ ) sample F2 (diffractogram b), g) sample F3 (diffractogram c), h) IBP sodium, i) mannitol $\delta$, and j) sample F4 (diffractogram d). 


\section{Crystalline state of IBP in freeze dried samples}

X-ray powder diffraction of lyophilized samples was carried out to compare crystalline IBP or IBP sodium salt with the IBP form in samples F1 to F4. Diffractograms of lyophilized powders F1-F4 in Fig. 2 show high intensity diffraction lines denoting their crystalline nature, but none of the diffraction lines indicate the crystalline form of IBP molecule with diffraction lines at $6.10^{\circ}, 16.61^{\circ}, 17.65^{\circ}, 19.50^{\circ}, 20.20^{\circ}, 22.37^{\circ} 2 \Theta$ degrees. The results of crystalline IBP are in good agreement with data presented by Potta et al. (9). In diffractograms of samples F1 and F2 (Fig. 2a,b), only diffraction lines of the crystalline phase of excipients can be observed, i.e., diffraction lines of $\mathrm{NaCl}$ present in sample $\mathrm{F} 1$ - see in Fig. $2 \mathrm{a}$ at $2 \Theta 31.76^{\circ}$ and of mannitol crystalline forms (polymorphic form $\alpha$ and $\beta$ ) present in F2 $\left(2 \Theta\right.$ at $\left.17.36^{\circ}, 20.45^{\circ}, 19.80^{\circ}\right)$ in Fig. 2b. Diffractograms of F3 and F4 (Fig. 2c,d), to which $\mathrm{NaOH}$ was added, show also the powerful crystalline nature of $\mathrm{NaCl}$ with one main peak (Fig. 2c) or mannitol with diffraction lines of a mixture of polymorphic forms (polymorphic form $\alpha, \beta$ and $\delta$ ) (Fig. 2d), additional unknown signals of crystalline structure (F3 at 2 $\Theta 3.59^{\circ}, 10.88^{\circ}$ and $22.22^{\circ}$ and $\mathrm{F} 4$ at $2 \Theta 3.62^{\circ}, 10.86^{\circ}$ ), which are close to characteristic diffraction lines of crystalline IBP sodium (at $2 \Theta 3.76^{\circ}, 11.16^{\circ}$ and $22.34^{\circ}$ ) and different from characteristic diffraction lines of crystalline IBP. Consequently, diffractograms of F1, F2, F3 and F4, all showing absence of characteristic diffraction lines of crystalline IBP, and diffractograms of F3 and F4 with diffraction lines similar to IBP sodium show clearly the presence of a modified structure of IBP molecule within a freeze dried product.

Further, characterization of lyophilized samples, mannitol, crystalline IBP and its sodium salt was carried out by DSC. The DSC curve b) in Fig. 3 shows a single, sharp endothermic peak at $77^{\circ} \mathrm{C}$, which corresponds to the melting point of crystalline IBP and

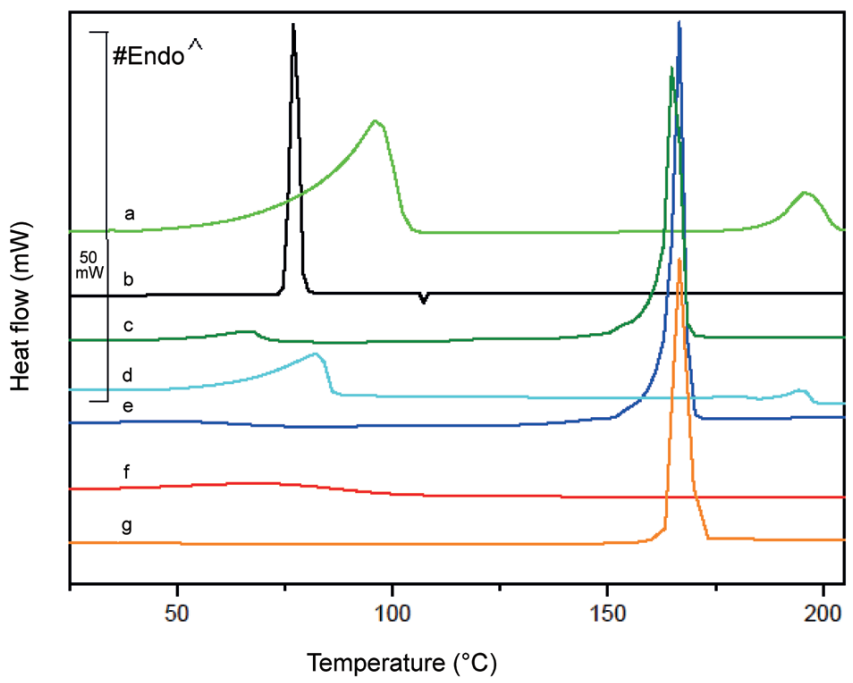

Fig. 3. DSC thermogram of: a) IBP sodium, b) crystalline IBP c) sample F4, d) sample F3, e) sample F2, f) sample F1, and g) mannitol. 
is in good correlation $\left(77.3^{\circ} \mathrm{C}\right)$ with the melting point determined by Lee et al. (24). However, in samples F1-F4, no endothermic peak indicating melting of the crystalline form of IBP can be observed. They rather show a clear change of the melting point and enthalpy compared to crystalline IBP. In sample F3, lower melting enthalpy and shift of the endothermic peak of IBP sodium salt was detected, indicating its presence, while in F2 and F4 a thermal effect was observed at higher temperature, with $t_{\text {onset }}$ at $162.9^{\circ} \mathrm{C}$ for $\mathrm{F} 2$ and $162.4^{\circ} \mathrm{C}$ for $\mathrm{F} 4$, indicating the presence of crystalline mannitol with the melting point at $170{ }^{\circ} \mathrm{C}$, since $\mathrm{F} 2$ and $\mathrm{F} 4$ formulations contain a 10 times larger amount of mannitol than IBP. According to literature data, IBP arginine, which might be present in F1 and F2, has a melting point at $170^{\circ} \mathrm{C}(34)$, while endothermic events for IBP sodium salt depend on its crystal form ( 99.2 and $\left.199.6^{\circ} \mathrm{C}\right)$, which is in good agreement with the DSC curve a) in Fig. 3. (24). The presence of IBP arginine was not detected in F2, while no thermal change was noticed at all in the thermogram of F1; thus the existence of crystalline IBP or coexistence of crystalline IBP and its salt could not be observed. It could be therefore presumed that IBP in sample F1 was amorphous, which is in correlation with the results obtained with XRPD and also ssNMR. Further, DSC thermograms are in good agreement with the XRPD findings discussed above and with Raman and ssNMR studies discussed below. DSC analyses confirmed the change of physical structure of crystalline IBP in all four lyophilized samples.

To study the possible interactions between IBP and excipients, Raman analysis was carried out. Raman spectra presented in Fig. 4 indicate a clear difference between sample F1 and crystalline IBP, while there is only a small difference between F3 and IBP sodium. No characteristic absorption band of IBP at approximately $834 \mathrm{~cm}^{-1}$ (complex vibration with predominant $\mathrm{CH}$ bond out of plane bending of aromatic ring) can be identified in $\mathrm{F} 1$,

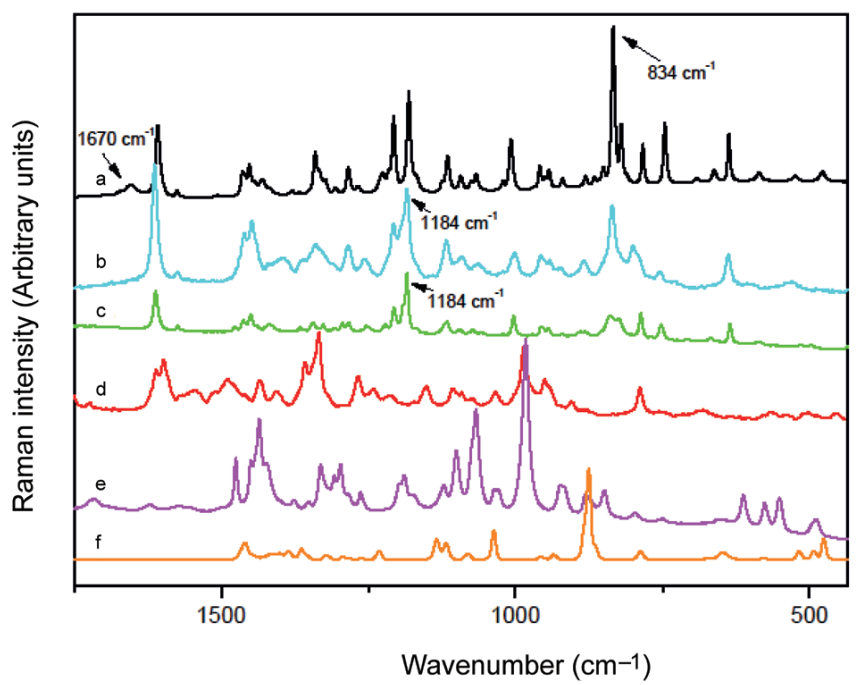

Fig. 4. Raman spectra of: a) crystalline IBP, b) sample F3, c) IBP sodium, d) sample F1 e) L-arginine, and f) mannitol. 


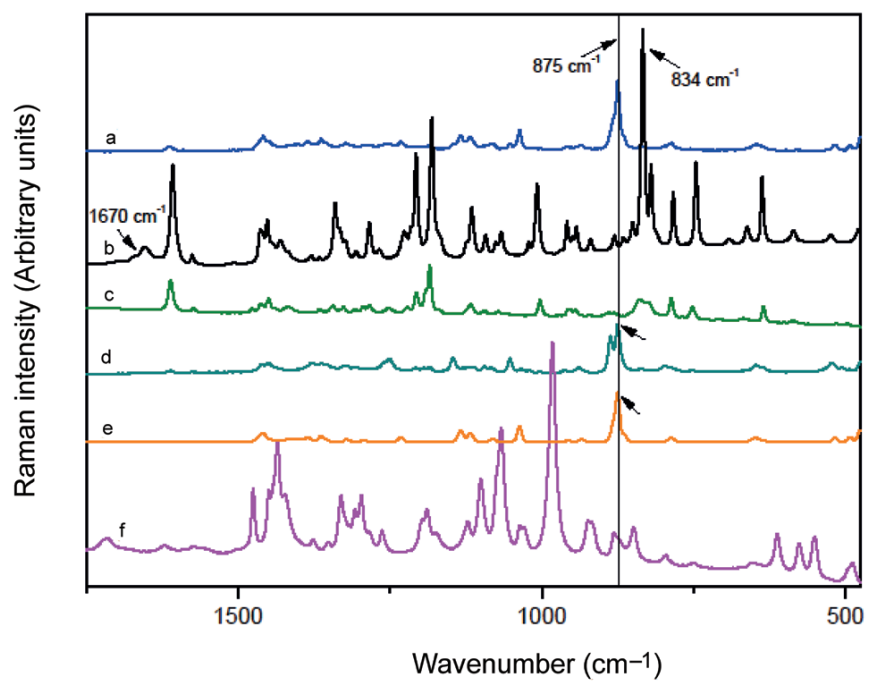

Fig. 5. Raman spectra of: a) sample F2, b) crystalline IBP, c) IBP sodium, d) sample F4, e) mannitol, and f) L- arginine.

while the characteristic absorption band of IBP sodium at $1184 \mathrm{~cm}^{-1}\left(\mathrm{C}_{7}-\mathrm{C}_{10}\right.$ stretching part of the molecule $\left(\mathrm{C}_{7}\right.$ aromatic atom) $)$ can be identified in $\mathrm{F} 3\left(1184 \mathrm{~cm}^{-1}\right)$ but with reduced intensity. Hence, it can be assumed that the modified IBP molecule is present, most probably in deprotonated form.

On the other hand, in F2 and F4 (Fig. 5), Raman absorption bands at $875 \mathrm{~cm}^{-1}$ of mannitol are dominant, which can be assigned to the lower drug content and 10 times higher amount of mannitol. Nevertheless, the disappearance of characteristic IBP absorption bands in F2 and F4 samples can also indicate a change in IBP molecule.

Raman analyses of all F1-F4 samples clearly show the disappearance of absorption bands at $1670 \mathrm{~cm}^{-1}$, which are characteristic for the $\mathrm{COOH}$ group and are an absolute indication that deprotonation of IBP molecule in lyophilized samples has occurred; ionized carbonyl $\left(\mathrm{COO}^{-}\right)$group is therefore present, as an indication of IBP salt formation with the later proven better aqueous solubility.

To obtain additional information regarding the crystalline structure of lyophilized samples, a solid state NMR (ssNMR) study was performed and is given in Fig. 6 and Fig. 7 .

In ${ }^{1} \mathrm{H}$ NMR spectra (Fig. 6), a signal at $\delta 12.7$ ppm was observed only in the spectrum of crystalline IBP and was assigned to the proton within the $\mathrm{COOH}$ group involved in intermolecular hydrogen bonds, which was already discussed and confirmed by the presence of dimeric structure by Kotar et al. (3). Signals of IBP sodium salt exhibited slightly narrower lines in comparison with the signals observed for crystalline IBP, which is in agreement with the data reported by Geepi et al. (35) and indicates higher molecular mobility of IBP sodium. Lack of signals corresponding to protons involved in hydrogen bonds in ${ }^{1} \mathrm{H}$ NMR spectra of F1 to F4 indicates transfer of the acidic proton and thus formation of 
arginine/sodium salt of IBP. It is noteworthy that the mentioned signal is not observed in IBP sodium either, while it is clearly seen in crystalline IBP.

Additional information was obtained by using ${ }^{13} \mathrm{C}$ CP-MAS NMR spectra (Fig. 7). It was already noted by Kotar et al. (3) that single signals for individual carbon atoms had been observed for crystalline IBP, while the spectrum of its sodium salt exhibited mostly two signals per carbon atom. Differences between crystalline IBP and IBP sodium can be nicely distinguished in the spectral region corresponding to the carboxylic group. Carbon signal in $\mathrm{COOH}$ of crystalline IBP was observed at $\delta 182.8 \mathrm{ppm}$, while it was at $\delta 185.0$ and $183.1 \mathrm{ppm}$ in F2, at $\delta 185.1$ and $184.0 \mathrm{ppm}$ in F3 and at $\delta 184.0 \mathrm{ppm}$ in F4 sample. Signals observed in ${ }^{13} \mathrm{C} \mathrm{CP-MAS} \mathrm{NMR} \mathrm{spectra} \mathrm{of} \mathrm{lyophilized} \mathrm{samples} \mathrm{F3} \mathrm{and} \mathrm{F4} \mathrm{are} \mathrm{in} \mathrm{better} \mathrm{agree-}$ ment with IBP sodium; they were observed at $\delta 184.8$ and $183.9 \mathrm{ppm}$. The difference between the F1 carbon signal at $\delta 182.5$ and crystalline IBP is smaller, which can be attributed to the amorphous phase of IBP arginate (salt form) in F1. Amorphous phase is nicely reflected in broader signals $(36,37)$ observed for F1, while F2, F3 and F4 have a crystalline nature, which is in correlation with DSC and XRPD results.

Major differences between F1/F3 with $\mathrm{NaCl}$ and F2/F4 with mannitol, as isotonicity adjustment agents, were detected in the $\delta 60-70$ ppm region, where mannitol signals resonated. In samples F1 and F2, signals of L-arginine were detected, with chemical shifts slightly different from that observed for pure L-arginine. The greatest difference was ob-

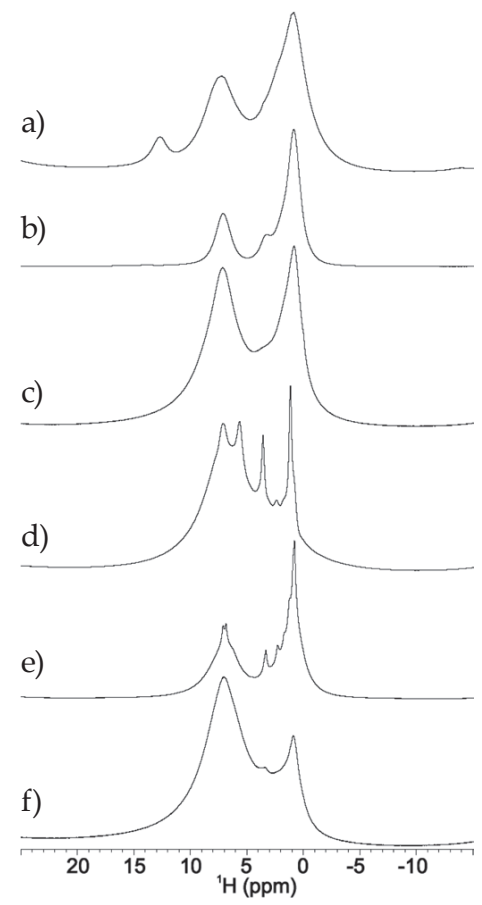

Fig. 6. ${ }^{1} \mathrm{H}$ NMR MAS spectra of: a) crystalline IBP, b) IBP sodium, c) sample F1, d) sample F2, e) sample F3, and f) sample F4. 
served for carboxyl carbon atom. In the case of pure L-arginine, the carboxyl carbon atom resonated at $\delta 180.2$ and $179.0 \mathrm{ppm}$, while in F1 and F2 it appeared at approximately $\delta 175.1$ ppm and $173.0 \mathrm{ppm}$, respectively. On the other hand, only a small difference in chemical shift of the carbon atom of the guanidine group was observed. In pure L-arginine, F1 and F2 carbon atoms of the guanidine group resonated at $\delta 158.3,157.7$ and $157.8 \mathrm{ppm}$, respectively. This can be attributed to arginine salt of IBP through protonation of amino group, which is close to the carboxyl group.

\section{Solubility enhancement}

The main purpose of the preparation of the freeze dried product was to improve the solubility of poorly aqueous soluble IBP. Therefore, solubility characteristics of the crystalline drug and freeze dried samples were investigated.

Results presented in Fig. 8 show that crystalline drug had the lowest solubility, whereas the highest solubility was observed in sample F1. Since literature data for aqueous solubility of IBP are inconsistent, the solubility test of crystalline IBP used for F1-F6 experiments was performed. Determined aqueous solubility of $0.2 \mathrm{mg} \mathrm{mL}^{-1}$ was in reasonable agreement with some literature values $\left(0.12 \mathrm{mg} \mathrm{mL}^{-1}\right)$ (5) but inconsistent with the data presented by Potta et al. ( $3.7 \mathrm{mg} \mathrm{mL}^{-1}$ ) (9). Nevertheless, the solubility of IBP in lyophilized samples of F1-F4, with $\mathrm{pH}$ of solution from 6 to 7 after reconstitution, was significantly improved and was as much as 80 -fold higher; between 17.6 to $22.7 \mathrm{mg} \mathrm{mL}^{-1}$.

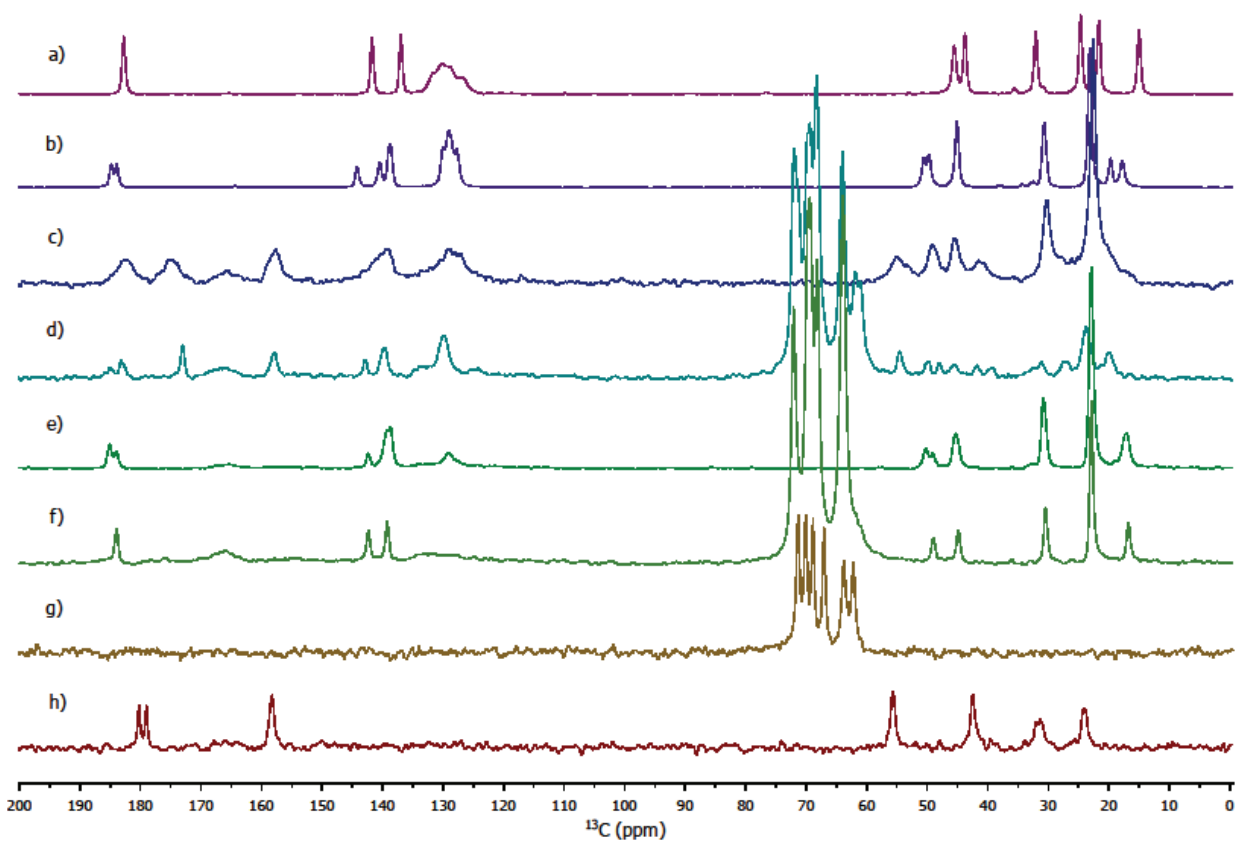

Fig. $7 .{ }^{13} \mathrm{C}$ NMR MAS spectra of: a) crystalline IBP, b) IBP sodium, c) sample F1, d) sample F2, e) sample F3, f) sample F4, g) mannitol, and h) L-arginine. 


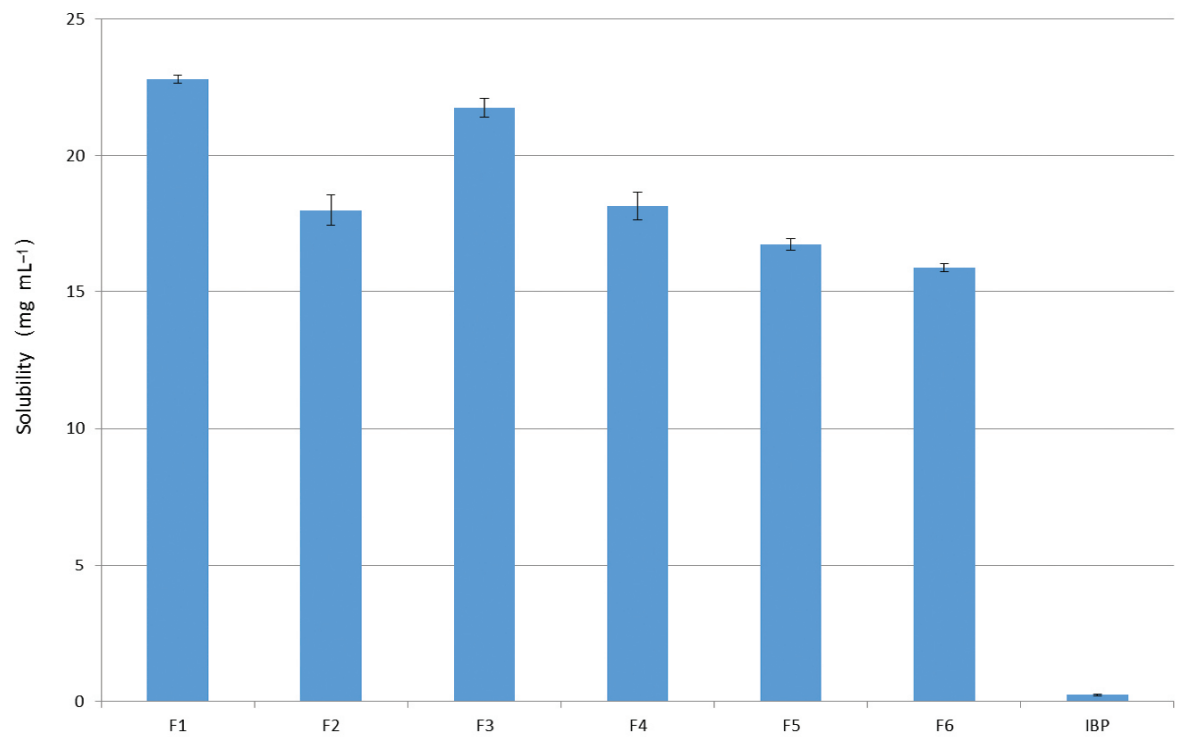

Fig. 8. Solubility of lyophilized samples F1-F6 and crystalline IBP molecule.

Finally, the solubility study confirmed the results of reconstitution time of F1-F4 formulations, while for F5 and F6, which have only slightly lower IBP solubility compared to F1-F4, the results are contradictory.

As already described by Kitak et al. (38) and Bustamante et al. (39), an expected increase in solubility can be observed, which is caused by the formation of sodium or arginine salt. Replacement of the acidic proton significantly increases Lewis base properties, therefore the highest solubility is found in proton donor solvents such as water (39). However, according to the results, strong influence of the excipients and the technological process was demonstrated. Higher solubility was noticed in lyophilizates with added $\mathrm{NaCl}$ (F1, F3), which was also supported by Stoyanova et al. (7), who studied the influence of electrolytes on the solubility of crystalline IBP in surfactant solution. Surprisingly, we have found that formulations with glucose and sucrose (samples F5 and F6) had an adverse effect on the appearance of solution after reconstitution, while solubility of IBP was clearly improved and comparable to F1-F4. However, the results indicate that the composition formula together with the chosen process parameters of freeze drying were not optimal for formulations with glucose and sucrose.

Finally, all results obtained by solid state characterization techniques, like Raman, DSC and X-ray analysis, showed marked changes in the nature of the drug prepared by the freeze drying technique. All results are actually in good agreement and undoubtedly confirm the absence of crystalline IBP in all lyophilized samples. In addition, the ssNMR study showed clear deprotonation of the carboxylic group in ${ }^{1} \mathrm{H}$ (Fig. 6) and a slight change in ${ }^{13} \mathrm{C}$ spectra (Fig. 7), which indicates salt formation caused by alkaline excipients (L-arginine or sodium hydroxide). 
Results are also supported by $\Delta \mathrm{p} K_{\mathrm{a}}$ calculation, which states that if the difference between the $\mathrm{pK}_{\mathrm{a}}$ of the base (arginine or $\mathrm{NaOH}$ ) and of the acid (IBP) is greater than three units, the material is most likely a salt. In our case, the difference of 4.6 in F1-F2 (L-arginine) and of $9.4(\mathrm{NaOH})$ in $\mathrm{F} 3-\mathrm{F} 4$ confirms high preference for the salt form.

Furthermore, solubility of all freeze dried formulations confirmed the change in the molecular nature of IBP, which consequently provided higher solubility compared to crystalline IBP. Moreover, the stability study of the freeze dried products after 1 month storage at $40{ }^{\circ} \mathrm{C}, 75 \% \mathrm{RH}$, confirmed that the salt formation did not have any adverse effect on the stability of pure drug and therefore good quality of the lyophilized product was obtained.

\section{CONCLUSIONS}

In the present study, solubilization for the parenteral freeze dried product with ibuprofen was demonstrated. In order to follow solubility enhancement and isotonicity of the dissolved product at the same time, excipients were selected very cautiously. However, it was surprising that the chosen technological process in correlation with excipients could adversely affect the appearance of reconstituted solution, since formulation with glucose and sucrose with the same $\mathrm{pH}$ of the solution and reconstitution time was not accomplished.

Solid state characterization techniques showed a clear change of the IBP molecule in freeze dried samples, in most cases as deprotonation of the carboxylic group, which indicates salt and overrules co-crystal formation. Furthermore, significant higher solubility of all freeze dried formulations also confirmed modification of the molecular nature of IBP.

Nevertheless, in-situ formation of IBP salts, i.e. arginate (F1, F2) or sodium salt (F3, F4), as well as isotonicity of the reconstituted product, further emphasized salt formation and the freeze drying process method, which can open new possibilities in the development of parenteral forms of class II molecules, which are weak acids.

Acknowledgments. - The authors thank Krka d.d., Novo Mesto, for supporting this study and the Slovenian NMR Center, National Institute of Chemistry, for NMR analyses.

Acronyms, abbreviations, symbols. - BCS - Biopharmaceutical classification system; $\mathrm{COO}^{-}$- carbonyl group; $\mathrm{COOH}$ - carboxyl group; $\mathrm{CP}$ - cross polarization; $\mathrm{DSC}$ - differential scanning calorimetry; FDA - Food and Drug Administration; IBP - ibuprofen; MAS - magic-angle spinning; ODT - orodispersible tablet; ssNMR - solid state nuclear magnetic resonance; WFI - water for injection; XRPD - X-ray powder diffractometry.

\section{REFERENCES}

1. P. Khadka, J. Ro, H. Kim, I. Kim, J. T. Kim, H. Kim, J. M. Cho, G. Yun and J. Lee, Pharmaceutical particle technologies: An approach to improve drug solubility, dissolution and bioavailability, Asian J. Pharm. Sci. 9 (2014) 304-316; https://doi.org/10.1016/j.ajps.2014.05.005

2. K. T. Savjani, A. Gajjar and J. K. Savjani, Drug solubility: Importance and enhancement techniques, International Scholarly Research Network, ISRN Pharm. 12 (2012). Article ID 195727; http:// dx.doi.org/10.5402/2012/195727

3. A. Kotar, M. Kotar, P. Šket and J. Plavec, Potential of solid-state NMR and SEM in characterization of tablets of ibuprofen, Curr. Pharm. Anal. 11 (2015) 124-130; https://doi.org/10.2174/1573412910666 141111231325 
4. A. G. Martinez, B. E. Rodrigez, A. P. Roca and A. M. Ruiz, Intravenous ibuprofen for treatment of post-operative pain: A multicenter, double blind, placebo-controlled, randomized clinical trial, Plos One 11 (2016) 1-16; https://doi.org/10.1371/journal.pone.0154004

5. J. Nerurkar, J. W. Beach, M. O. Park and H. W. Jun, Solubility of ( \pm )-ibuprofen and $S(+)$-ibuprofen in the presence of cosolvents and cyclodextrins, Pharm. Dev. Technol. 10 (2005) 413-421; https://doi. org/10.1081/PDT-54446

6. A. R. Fernandes, N. R. Ferreira, J. F. Fangueiro, A. C. Santos, F. J. Veiga, C. Cabral, A. M. Silva and E. B. Souto, Ibuprofen nanocrystals developed by $2^{2}$ factorial design experiment: A new approach for poorly water-soluble drugs, Saudi Pharm. J. 25 (2017) 1117-1124; https://doi.org/10.1016/j. jsps.2017.07.004

7. K. Stoyanova, Z. Vinarov and S. Tcholakova, Improving ibuprofen solubility by surfactant-facilitated self-assembly into mixed micelles, J. Drug. Deliv. Sci. Tec. 36 (2016) 208-215; https://doi. org/10.1016/j.jddst.2016.10.011

8. A. Tan, N. G. Eskandar, S. Rao and C. A. Prestidge, First in man bioavailability and tolerability studies of a silica-lipid hybrid (Lipoceramic) formulation: A phase I study with ibuprofen, Drug. Deliv. Trans. Re. 4 (2014) 212-221; https://doi.org/10.1007/s13346-013-0172-9

9. S. G. Potta, S. Minemi, R. K. Nukala, C. Peinado, D. A. Lamprou, A. Urquhart and D. Douroumis, Preparation and characterization of ibuprofen solid lipid nanoparticles with enhanced solubility, J. Microencapsul. 28 (2011) 74-81; http://doi.org/ 10.3109/02652048.2010.529948

10. S. Melzig, D. Niedbalka, C. Schilde and A. Kwade, Spray drying of amorphous ibuprofen nanoparticles for the production of granules with enhanced drug release, Colloids Surf. A Physicochem. Eng. Asp. 536 (2018) 133-141; https://doi.org/10.1016/j.colsurfa.2017.07.028

11. D. Bolten, R. Lietzow and M. Türk, Solubility of ibuprofen, phytosterol, salicylic acid, and naproxen in aqueous solutions, Chem. Eng. Technol. 36 (2013) 426-434; https://doi.org/10.1002/ceat.201200510

12. A. A. Mamun, A. Masum, F. Sharmin, A. Islam and S. Reza, Enhancement of solubility and dissolution characteristics of ibuprofen by solid dispersion technique, Dhaka University, J. Pharm. Sci. 11 (2012) 1-6; https://doi.org/10.3329/dujps.v11i1.12480

13. M. M. Gupta, M. G. Patel, N. S. Patel and M. Kedawat, Enhancement of dissolution rate of ibuprofen by preparing solid dispersion using different methods, Int. J. Pharm. Pharm. Sci. 3 (2011) 204206.

14. R. P. Dugar, B. Y. Gajera and R. H. Dave, Fusion method for solubility and dissolution rate enhancement of ibuprofen using block copolymer poloxamer 407, AAPS PharmSciTech. 17 (2016) 1428-1440; http://doi.ord/10.1208/s12249-016-0482-6

15. M. Dixit, P. Kulkarni, P. Selvam and S. Mohsin, Preparation and characterization of freeze dried crystals of ibuprofen, Int. Res. J. Pharm. 2 (2011) 255-258.

16. Karsono, J. Tanuwijaya and D. Fatma, Formulation of ibuprofen orally disintegrating tablets (ODTs) by lyophilization method using gelatin and mannitol, Int. J. PharmTech. Res. 6 (2014) 9961002.

17. M. Di Cagno, P. C. Stein, N. Skalko- Basnet, M. Brandl and A. Bauer-Brandl, Solubilization of ibuprofen with $\beta$-cyclodextrin derivatives: Energetic and structural studies, J. Pharm. Biomed. Anal. 55 (2011) 446-451; https://doi.org/10.1016/j.jpba.2011.02.022

18. K. Kagkadis, D. M. Rekkas, P. Dallas and N. H. Choulis, A freeze-dried injectable form of ibuprofen: development and optimisation using response surface methodology, PDA J. Pharm. Sci. Technol. 50 (1996) 317-323; https://doi.org/10.1016/S0378-5173(97)00332-3

19. S. K. Patel, D. Kumar, A. P. Waghmode and A. S. Dhabale, Solubility enhancement of ibuprofen using hydrotopic agents, Int. J. Pharm. Life Sci. 2 (2011) 542-545.

20. S.-H. Park and H.-K. Choi, The effects of surfactants on the dissolution profiles of poorly watersoluble acidic drugs, Int. J. Pharm. 321 (2006) 35-41; https://doi.org/10.1016/j.ijpharm.2006.05.004 
21. S. H. Soltanpour and A. Jouyban, Solubility of acetaminophen and ibuprofen in binary and ternary mixtures of polyethylene glycols 200 and 400, propylene glycol, and water at $25^{\circ} \mathrm{C}, \mathrm{Chem}$. Eng. Commun. 201 (2014) 1606-1619; https://doi.org/10.1080/00986445.2013.821609

22. M. A. Filippa and E. I. Gasull, Ibuprofen solubility in pure organic solvents and aqueous mixtures of cosolvents: Interactions and thermodynamic parameters relating to the solvation process, Fluid Phase Equilibr. 354 (2013) 185-190; https://doi.org/10.1016/j.fluid.2013.06.032

23. M. G. Volonte, P. D. Valora, A. Cingolani and M. Ferrara, Stability of ibuprofen in injection solutions, Am. J. Health-Syst. Ph. 62 (2005) 630-633.

24. T. Lee and Y. W. Wang, Initial salt screening procedures for manufacturing ibuprofen, Drug Dev. Ind. Pharm. 35 (2009) 555-567; https://doi.org/10.1080/03639040802459452

25. U.S. Food and Drug Administration; FDA Approved Drugs; Ibuprofen http://www.accessdata.fda. gov/scripts/cder/drugsatfda/index.cfm?fuseaction=Search.SearchAction\&SearchTerm=ibuprofen \&SearchType=BasicSearch; access date April 2017.

26. The ABDA - Federal Union of German Associations of Pharmacists; access date April 2017.

27. Highlights of prescribing information; NDA 022348 Caldolor; https:/www.accessdata.fda.gov/ drugsatfda_docs/label/2016/022348s010lbl.pdf; access date May 25, 2018.

28. J. Manrique and F. Martinez, Solubility of ibuprofen in some ethanol + water cosolvent mixtures at several temperatures, Lat. Am. J. Pharm. 26 (2007) 344-354.

29. M. L Hart, D. P Do, R. A Ansari and S.A A. Rizvi, Brief overview of various approaches to enhance drug solubility, J. Dev. Drugs 2 (2013) 1-7; https://doi.org/10.4172/2329-6631.1000115

30. J. N. Patel, D. M. Rathod, N. A. Patel and M. K. Modasiya, Techniques to improve the solubility of poorly soluble drugs, Int. J. Pharm. Life Sci. 3 (2012) 1459-1469.

31. G. G. Z. Zhang, S. Y. L. Paspal, R. Suryanarayanan and D. J. W. Grant, Racemic species of sodium ibuprofen: Characterization and Polymorphic Relationships, J. Pharm. Sci. 92 (2003) 1356-1366; https://doi.org/10.1002/jps.10393

32. J. C. Kasper and W. Friess, The freezing step in lyophilisation: Physico-chemical fundamentals, freezing methods and consequences on process performance and quality attributes of biopharmaceuticals, Eur. J. Pharmaceut. Biopharmaceut. 78 (2011) 248-263; https://doi.org/10.1016/j. ejpb.2011.03.010

33. R. C. Rowe, P. J. Sheskey and M. E. Quinn, Mannitol, Sodium chloride, Dextrose and Succrose, in Handbook of Pharmaceutical Excipients (Ed. R. C. Rowe), $6^{\text {th }}$ ed., Pharmaceutical Press and American Pharmacists Association, London/Washington, UK/USA 2009, pp. 426, 641, 224 and 704.

34. S. R.-Royo, A. Martin, A. L. Simplicio, A. Matias, G. Bansaghi and M. J. Cocero, Separation of ibuprofen enantiomers by diastereomic salt formation and antisolvente precipitation in supercritical carbon dioxide, Poster 89, http://www.isasf.net/fileadmin/files/Docs/Graz/HtmlDir/Papers/ P89.pdf; access date May 25, 2018

35. M. Geppi, S. Guccione, G. Mollica, R. Pignatello and C. Veracini, Molecular properties of ibuprofen and its solid dispersions with eudragit RL100 studied by solid state nuclear magnetic resonance, Pharm. Res. 22 (2005) 1544-1555; https://doi.org/10.1007/s11095-005-6249-5

36. F. G. Vogt, Characterization of pharmaceutical compounds by solid-state NMR, eMagRes. 4 (2015) 255-268; https://doi.org/10.1002/9780470034590.emrstm1393

37. R. K. Harris, Applications of solid-state NMR to pharmaceutical polymorphism and related matters, J. Pharm. Pharmacol. 59 (2007) 225-239; https://doi.org/10.1211/jpp.59.2.0009

38. T. Kitak, A. Dumičić, O. Planinšek, R. Šibanc and S. Srčič, Determination of solubility parameters of ibuprofen and ibuprofen lysinate, Molecules 20 (2015) 21549-21568; https://doi.org/10.3390/molecules201219777

39. P. Bustamante, M. A. Peña and J. Barra, The modified extended Hansen method to determine partial solubility parameters of drug containing a single hydrogen bonding group and their sodium derivatives: benzoic acid/Na and ibuprofen/Na, Int. J. Pharm. 194 (2000) 117-124; https://doi. org/10.1016/S0378-5173(99)00374-9 